\title{
O Sistema Oligárquico Representativo da Primeira República
}

\author{
Wanderley Guilherme dos Santos
}

Professor titular (aposentado) de Teoria Política da Universidade Federal do Rio de Janeiro (UFRJ). E-mail: wanderleyguilhermesantos@gmail.com

\section{ANTECEDENTES: INDICADORES COMPARADOS DE RENOVAÇÃO PARLAMENTAR E ESTABILIDADE GOVERNAMENTAL}

工 m 7 de setembro de 2008, o Brasil completou 182 anos de vida jurídica independente, calculados a partir da investidura da primeira legislatura da Câmara dos Deputados, em 1826. Desses quase dois séculos de soberania formal, 63 anos foram transpostos sob regime monárquico semiabsolutista (1826-1889); 40 anos como república oligárquica clássica (1890-1930); 6, (1931-1937), como oligarquia não institucionalizada; 7, como ditadura civil (1937/38-1945); 18, (1946-1964), como democracia constitucional incompleta (restrição ao voto dos analfabetos); 22 anos como ditadura militar (1964-1986) e os últimos 22 como democracia constitucional, sem restrições de participação além de idade mínima (sendo a participação eleitoral voluntária para maiores de 16 anos, estes incluídos, e compulsória a partir dos 18 anos de idade).

Durante o período imperial, o mais longevo até o presente, o Brasil pode ser classificado como uma monarquia absolutista mitigada. A existência de um arremedo de sistema parlamentarista não foi suficiente para descaracterizar o arbítrio próprio do absolutismo implícito no conceito de Poder Moderador. Era o Imperador, em sua face absolu-

DADOS - Revista de Ciências Sociais, Rio de Janeiro, vol. 56, n- 1, 2013, pp. 9 a 37. 
tista de "moderador", que fazia e desfazia gabinetes, concedia mandatos vitalícios aos senadores e conselheiros do Estado, ademais de distribuir comendas e títulos nobiliárquicos. O exercício pouco violento do poder, comparativamente às repúblicas sul-americanas do período, a relativa tolerância com a oposição parlamentar e a imprensa não destituía o sistema de sua condição institucional centralizadora e arbitrária. Assim o sofriam não apenas os oposicionistas do regime, depois de 1870 quando se organiza o Partido Republicano, mas também os adeptos da Monarquia, quando desvalidos das graças do trono. O romancista e político José de Alencar foi um desses e, entre outros escritos, deixou irrespondível crítica intelectual à monarquia brasileira em seu extraordinariamente rico O Sistema Representativo (Alencar, 1868).

A qualificação de crítica intelectual aos escritos de Alencar deve ser estendida a todos os políticos, jornalistas e militantes de oposição, em geral, durante o período monárquico, para indicar que uma das possíveis razões da reverenciada benevolência do Imperador se devesse à quase absoluta impotência da oposição, mesmo radical, em ameaçar sequer um centésimo do poder imperial. Para além das diatribes nos jornais e da retórica flamejante da tribuna parlamentar, nada podiam fazer os oposicionistas para limitar o uso do institucionalmente irresponsável Poder Moderador. Além de sempre constituírem a minoria da nação, isto é, daquele reduzido grupo de brasileiros em condições de atender à legislação e participar da vida pública. É de notar que a extensão dos direitos de voto, com a gradativa redução nos requisitos de renda, tendo permitido a criação de um eleitorado basicamente urbano, foi podado ao final do período com a introdução do requisito de educação. $\mathrm{Na}$ última eleição legislativa do Império (20a legislatura - 1886/1889), o comparecimento alcançou apenas 117.671 eleitores. A grande maioria dos políticos, durante todo o período, era fiel às instituições do regime e atendia aos desejos do Poder Moderador, em suas intervenções na vida política e dissoluções de gabinete. A composição das câmaras subsequentes sempre trazia um contingente de novos membros, pelo menos em relação à Câmara anterior, selecionados pelos poderes locais, e futuros votos garantidos para as políticas oficiais. A Tabela 1 expõe as taxas de renovação bruta da Câmara dos Deputados para todo o período de 63 anos de seu ininterrupto funcionamento.

As taxas de renovação são bastante elevadas, com uma média de $65 \%$ a cada nova legislatura. O rodízio dos representantes oligárquicos facilitava a governabilidade, sem desgastantes e prolongados conflitos en- 
Tabela 1

Taxa de Renovação Bruta - Império Câmara dos Deputados

Brasil

\begin{tabular}{c|c|c}
\hline Legislatura & Período & Brasil \\
\hline $\mathbf{2}$ & $1830-1833 / 1826-1829$ & 65,00 \\
$\mathbf{3}$ & $1834-1837 / 1830-1833$ & 62,50 \\
$\mathbf{4}$ & $1838-1841 / 1834-1837$ & 65,35 \\
$\mathbf{5}$ & $1843-1844 / 1838-1841$ & 75,25 \\
$\mathbf{6}$ & $1845-1847 / 1843-1844$ & 79,61 \\
$\mathbf{7}$ & $1848 / 1845-1847$ & 56,60 \\
$\mathbf{8}$ & $1850-1852 / 1848$ & 82,88 \\
$\mathbf{9}$ & $1853-1856 / 1850-1852$ & 50,44 \\
$\mathbf{1 0}$ & $1857-1860 / 1853-1856$ & 81,70 \\
$\mathbf{1 1}$ & $1861-1864 / 1857-1860$ & 42,62 \\
$\mathbf{1 2}$ & $1864-1866 / 1861-1864$ & 61,48 \\
$\mathbf{1 3}$ & $1867-1868 / 1864-1866$ & 59,48 \\
$\mathbf{1 4}$ & $1869-1872 / 1867-1868$ & 91,80 \\
$\mathbf{1 5}$ & $1872-1875 / 1869-1872$ & 56,56 \\
$\mathbf{1 6}$ & $1878 / 1872-1875$ & 45,90 \\
$\mathbf{1 7}$ & $1878-1881 / 1878$ & 86,07 \\
$\mathbf{1 8}$ & $1881-1884 / 1878-1881$ & 70,49 \\
$\mathbf{1 9}$ & $1885 / 1881-1884$ & 46,40 \\
$\mathbf{2 0}$ & $1886-1889 / 1885$ & 60,00 \\
\hline
\end{tabular}

Fonte: Japeri (1979).

tre o Executivo e o Legislativo, ao mesmo tempo em que dava oportunidade de participação na vida pública aos membros das reduzidas elites locais do século XIX. Nem foi o caso de que participantes de uma Câmara recém-dissolvida voltassem ao Parlamento uma ou duas legislaturas depois. A distribuição do número de mandatos obtidos pelos representantes eleitos encontra-se na Tabela 2.

Foram eleitos, ao longo de todo o período, 1.129 deputados. Destes, 819 , ou $73 \%$ do total, só cumpriram um mandato, e 238, equivalentes a mais $21 \%$, participaram apenas de duas legislaturas. Somados, $94 \%$ de todos os deputados imperiais serviram, no máximo, por 6 anos, 10 deputados permaneceram 12 anos e somente 1 esteve na Câmara, tudo somado, por 18 anos, em 63 anos de atividade parlamentar ininterrupta. 
Tabela 2

Total de Mandatos de Deputados - Império

Câmara dos Deputados

Brasil

\begin{tabular}{lrrrrrr}
\hline No de vezes Eleito (s) & 1 & 2 & 3 & 4 & 5 & 6 \\
No de Deputados Eleito (s) & 819 & 238 & 59 & 10 & 2 & 1 \\
\hline
\end{tabular}

Fonte: Japeri (1979).

Se a rotação das elites parlamentares foi veloz, a estabilidade governamental, isto é, a permanência dos gabinetes e ministros não evidencia maior durabilidade. Distribuindo os gabinetes durante o Império em três períodos -1 Reinado (10 gabinetes), Regência (13 gabinetes) e 2음 Reinado (36 gabinetes) - Cléa Sarmento verificou em seu estudo sobre o Império que, em todos os períodos, o maior número de gabinetes durou no máximo até um ano e, em todos também, poucos ultrapassaram dois anos de duração. A informação completa está na Tabela 3.

Tabela 3

Duração dos Gabinetes Ministeriais no Império

\begin{tabular}{l|c|c|c}
\hline Duração & $\mathbf{1}^{\mathbf{0}}$ Reinado & Regência & 20 Reinado \\
\hline Até 1 ano & $60 \%$ & $85 \%$ & $47 \%$ \\
De 1 a 2 anos & $40 \%$ & $7,5 \%$ & $33 \%$ \\
2 anos e mais & - & $7,5 \%$ & $19 \%$ \\
\hline Total & $\mathbf{1 0 0 \%}$ & $\mathbf{1 0 0 \%}$ & $\mathbf{1 0 0 \%}$ \\
& $\mathbf{( 1 0 )}$ & $\mathbf{( 1 3 )}$ & $\mathbf{( 3 6 )}$ \\
\hline
\end{tabular}

Fonte: Sarmento (1986).

Em termos agregados, a taxa média de estabilidade governamental no Império (1822-1889) foi de 0,32, em métrica cujo valor máximo de estabilidade é 1,0 . Em todos os três períodos da cronologia imperial, quanto mais longa a duração, menor o número de gabinetes que dela usufruíram. A monarquia absolutista brasileira, com o concurso dos poderes escravistas locais, evitou que se formasse uma oposição parlamentar experimentada e duradoura, capaz de criar mecanismos de resistências ao Poder Moderador. Além da brevidade da carreira política dos parlamentares, em sua maioria, convém mencionar a esperta utilização imperial do recurso de alternar os dois principais partidos, Liberais e Conservadores, com a responsabilidade de constituir gabinetes. Em nenhum dos cálculos partidários, a opção de radicalizar a opinião contra o sistema oferecia perspectiva de bônus superior à da modera- 
ção, dependendo da reiteração desta a eventual oportunidade de voltar ao poder pelas mãos do Imperador. Não é surpresa, portanto, observar que a maioria dos gabinetes com vida mais longa foi conduzida por conservadores, como a Tabela 4 demonstra:

Tabela 4

Duração dos Gabinetes Ministeriais e Filiação Partidária no Segundo Reinado

\begin{tabular}{l|c|c|c|c}
\hline \multirow{2}{*}{ Duração } & \multicolumn{4}{|c}{ Filiação Partidária } \\
\cline { 2 - 5 } & Liberais & Conservadores & Conciliação* $^{*}$ & Total \\
\hline Até 1 ano & 30 & 7 & 10 & 47 \\
Entre 1 e 2 anos & 3 & 17 & 10 & 30 \\
Mais de 2 anos & 3 & 17 & 3 & 23 \\
\hline Total & $\mathbf{3 6 \%}$ & $\mathbf{4 1 \%}$ & $\mathbf{2 3 \%}$ & $\mathbf{1 0 0 \%}$ \\
& $\mathbf{( 1 1 )}$ & $\mathbf{( 1 2 )}$ & $\mathbf{( 7 )}$ & $\mathbf{( 3 0 )}$ \\
\hline
\end{tabular}

Fonte: Sarmento (1986).

* Inclui o Ministério da Conciliação (Paraná) e os da fase do Partido Progressista.

O controle das bases eleitorais exercido pela lavoura escravista foi excepcionalmente eficiente para garantir a estabilidade do regime, não obstante o conflito parlamentar e retórico entre a situação governamental e a oposição.

A implantação da República, em 1889, aboliu as instituições monárquicas, entre elas, a do Poder Moderador; ratificou a mobilidade relativa do fator trabalho, instituída pela Abolição da Escravatura no ano anterior; extinguiu completamente o requisito de renda para a participação eleitoral, à frente de todos os países em que existiam eleições, mas manteve os vetos à participação feminina e dos analfabetos. Instalava-se por inteiro o sistema representativo oligárquico, com todas as peculiaridades institucionais: conflito altamente regulado entre as elites e extensa exclusão nos direitos à participação.

A literatura internacional tem curiosa perversão de ótica sobre a história brasileira. Dá-se por assentado que a instabilidade comparada de alguns países do continente sul-americano, ou a que é atribuída ao agregado "América do Sul", pode ser creditada a cada um dos estados em particular. Falácia ecológica, naturalmente, posto que se a Bolívia, por exemplo, exibe um cadastro de golpes de estado superior ao da Argentina, não praticou, ao contrário desta, um prático genocídio de suas populações indígenas. O mesmo critério comparativo pode ser aplicado ao par Equador versus Chile. No caso do Brasil, é patente- 
mente falso que sua história republicana tenha sido testemunha de inúmeros golpes de estado, militares ou civis, assertiva trivial em todos os tratados internacionais sobre o país. Mais irregular ainda é verificar que a literatura nacional repete a proposição sem que, tanto em um caso quanto no outro, algum autor se dê ao trabalho de listar, comprovando-os, os episódios contabilizados. Nem, de fato, poderiam.

A verdade é que os primeiros quarenta anos da república oligárquica brasileira transcorreram sem qualquer transtorno sério e eficaz na obediência às normas políticas. Não houve interrupção nas eleições legislativas, não houve deposição de presidentes, antes de 1930, nem houve manifestações militares bem-sucedidas. Algumas tentativas de revolução na década de 1920, sim, embora todas fracassadas, violência na política local, sim, como é usual na política de sistemas oligárquicos, mas golpe de estado bem-sucedido, não. Ao contrário, todas as eleições presidenciais, seguidas da posse dos eleitos, foram pacíficas. As regras de competição intraoligárquicas foram eficazes a nível nacional, enquanto a nível local prevalecia a disputa com base no voto, na violência e na corrupção, esta última ausente, por desnecessária, das eleições presidenciais.

A partir de 1902, as eleições presidenciais eram decididas por um colégio informal de que faziam parte os representantes dos estados federados e a liderança governista. Na mesma eleição de 1902, o indicado Rodrigues Alves obteve 37 votos em 38 desse colégio. O dissidente, Quintino Bocayuva, lançou-se candidato nas eleições formais, e o resultado apontou 592.039 votos para Alves e 52.359 para Quintino. À exceção das eleições de 1922, de Artur Bernardes, todos os resultados exibiram a mesma e enorme vantagem em benefício do candidato governista, quando havia competição pela Presidência da República. Com efeito, das dez sucessões pós-Floriano Peixoto, e até Washington Luís, cinco não foram disputadas senão por um candidato, depois de obtido o consenso entre os "eleitores" privilegiados. A elevada coesão e integração dos oligarcas, cujas diferenças se manifestavam apenas durante as tratativas para escolha do prometido sucessor, garantiam a aceitação do nome do vitorioso, afastando qualquer ameaça de golpe de estado. $\mathrm{O}$ sistema oligárquico brasileiro propiciou quarenta anos de exemplar estabilidade institucional, sem prejuízo de ocasionais solavancos governamentais. $\mathrm{O}$ consenso prévio às disputas presidenciais garantia a estabilidade governativa das administrações, que transcorriam sem os grandes estremecimentos característicos das reformas ministeriais. 
Tomando as mudanças ministeriais como indicador de instabilidade, a taxa média de estabilidade governamental, medida pela rotatividade de ministros, alcançou o elevado valor de 0,68. Esse valor indica a probabilidade estatística de que um ministro, uma vez no cargo, nele continuasse até o fim do mandato presidencial ${ }^{1}$.

Ao longo desses quarenta anos, tendo a engenharia por estado de espírito e o ilusionismo como astúcia da expansão material, esquivou-se o Brasil republicano dos eternos retornos militaristas próprios da América subequatorial. Magnífico exemplo de eficiente sistema oligárquico, sucederam-se, no país, eleições legislativas e presidenciais ornamentadas pelos episódios que a tradição sancionava: violência e intimidação locais, empastelamento de meios de comunicação, fraudes antes, durante e depois dos pleitos, corrupção, posse negociada dos eleitos (para a Câmara e o Senado), em transcendente manobra sobre os resultados das urnas. Nenhuma interrupção do calendário eleitoral, contudo, ou extemporâneas substituições de presidentes por generais ou coronéis no comando de batalhões. Ensandecidos no cargo (Delfim Moreira) ou mortos súbitos (Afonso Pena e Rodrigues Alves), que os houve, cederam lugar aos vivos e sóbrios, tal como registrado na linha sucessória e conforme acordos previamente entretidos, rigorosamente acatados. Desempenho oligárquico impecável até 1930, nunca ameaçado a sério pelos inconsequentes surtos tenentistas do período. Estes, juvenis rebentos de heterogêneo estamento, espremidos entre afetados fazendeiros-capitalistas, que os ignoravam, e os peregrinos do trabalho, que desprezavam, não dispunham senão de rala percepção do real torvelinho em que nunca superaram a condição de marionetes.

Por certo, o consenso característico da sucessão presidencial não se reproduzia nas disputas locais, em que famílias competiam pelo privilégio de nomear o delegado, o juiz de direito, o diretor da escola pública e o arrecadador de impostos. À centralização federal correspondiam feudos paroquiais, suficientemente radicalizados como para substituir em grande parte a representação do estado na Câmara dos Deputados a cada eleição. A Tabela 5 registra a taxa de renovação bruta de cada legislatura, com a taxa média do período igual a 0,42.

A média não reflete a trajetória de cada uma das unidades da federação, claro, sendo esta uma das questões a enfrentar para melhor entendimento da operação real do sistema. Em números de elite, foram 1.305 deputados que ocuparam cadeiras da 21a à 35a legislatura, a maioria 
Tabela 5

Taxa de Renovação Bruta

Primeira República

Câmara dos Deputados (Brasil)

\begin{tabular}{l|c|c}
\hline Legislatura & Período & Brasil \\
\hline L 22 & $1891-1893$ & $\mathbf{0 , 1 7}$ \\
L 23 & $1894-1896$ & $\mathbf{0 , 6 3}$ \\
L 24 & $1897-1896$ & $\mathbf{0 , 4 4}$ \\
L 25 & $1900-1902$ & $\mathbf{0 , 4 6}$ \\
L 26 & $1903-1905$ & $\mathbf{0 , 4}$ \\
L 27 & $1906-1909$ & $\mathbf{0 , 4 2}$ \\
L 28 & $1909-1912$ & $\mathbf{0 , 4}$ \\
L 29 & $1912-1915$ & $\mathbf{0 , 4 8}$ \\
L 30 & $1915-1918$ & $\mathbf{0 , 4 6}$ \\
L 31 & $1918-1921$ & $\mathbf{0 , 4 1}$ \\
L 32 & $1921-1924$ & $\mathbf{0 , 4 1}$ \\
L 33 & $1924-1927$ & $\mathbf{0 , 4 3}$ \\
L 34 & $1927-1930$ & $\mathbf{0 , 4 1}$ \\
L 35 & $1930-1930$ & $\mathbf{0 , 3}$ \\
\hline
\end{tabular}

Fonte: Dados fornecidos pela Câmara dos Deputados, parte integrante da "Pesquisa de Deputados", que vem sendo desenvolvida por essa instituição. Autoria da organização dos dados e cálculos de renovação: Carlos Frederico Robbs Filho e Marcelle Marie Freitas Huet Rodrigues (coordenação: Wanderley Guilherme dos Santos (LEEX).

dos quais só dispôs de um mandato (40\%). A Tabela 6 revela quantos deputados cumpriram quantos mandatos durante o período considerado.

Acrescentado ao número de pessoas que só desfrutaram de um mandato o daqueles que exerceram dois (16\%), obtém-se que a maioria da elite parlamentar da Primeira República (57\%) não permaneceu na Câmara mais do que seis anos (era de três anos a extensão do mandato). Com realismo, é possível entender que os 30 personagens que usufruíram 8, 9 e 10 mandatos, somados aos 2 que estiveram presentes na Câmara durante 12 e 13 legislaturas, compõem a elite parlamentar do período, posto que os senhores locais destituíam de poder qualquer representante, quando eles assim supunham necessário, tal como os 840 deputados, dos 1.305 que passaram pela Câmara, e que lá estiveram não mais do que por um ou dois mandatos, poderiam atestar. 
Tabela 6

Total de Mandatos de Deputados Primeira República Câmara dos Deputados

Brasil

\begin{tabular}{lccccccccccccc}
\hline № de vezes Eleito(s) & 1 & 2 & 3 & 4 & 5 & 6 & 7 & 8 & 9 & 10 & 11 & 12 & 13 \\
№ de Deputados Eleito(s) & 526 & 314 & 163 & 133 & 60 & 44 & 33 & 16 & 10 & 4 & 0 & 1 & 1 \\
\hline
\end{tabular}

Fonte: Dados fornecidos pela Câmara dos Deputados, parte integrante da "Pesquisa de Deputados", que vem sendo desenvolvida por essa instituição. Autoria da organização dos dados e cálculos de renovação: Carlos Frederico Robbs Filho e Marcelle Marie Freitas Huet Rodrigues (coordenação: Wanderley Guilherme dos Santos (LEEX).

Será como rebeldia contra a sucessão de Washington Luiz, em 1930, que se inaugura outra etapa no século republicano brasileiro. Os 15 anos transcorridos entre o fim do domínio exclusivo da oligarquia clássica e a instauração de uma democracia constitucional incompleta (1930-1945) correspondem à demolição quase integral das bases econômicas da oligarquia tradicional, encerrada pelo período de ditadura militar iniciado em 1964. Em números agregados, foram 104 anos de incontrastável supremacia oligárquica na vida civil e parlamentar (1826-1930), parte dela fundada em regime econômico escravista (até 1888), e 34 anos de transição para superar uma economia agrária oligopolizada e decadente (1930-1964). No total, a transformação da sociedade brasileira de oligárquica-escravista em democrática e capitalista ocupou 164 dos 182 anos de vida nacional independente.

Embora relativamente clássica, a periodização sugerida é bastante controversa para fins de análises econômicas e políticas mais complexas. Mesmo com a exclusão do período imperial e escravista, não existe consenso sobre o fim do predomínio político oligárquico nem se dá por completada a transformação capitalista do país.

A análise política da Primeira República (1889-1930) deve se submeter aos constrangimentos impostos pela frágil posição do país no sistema internacional do comércio. Se considerações além das nacionais são imperiosas na investigação da política interna de todas as nações, essa necessidade é tanto maior quanto mais dependente das flutuações do sistema econômico mundial é a nação. Um entendimento reducionista dos constrangimentos explicaria as decisões de política nacional, durante o período, como resultado direto de solicitações estrangeiras. $\mathrm{Na}$ realidade, mesmo quando condições de emergência faziam das opiniões de credores no exterior uma variável crucial, opiniões que não podiam ser contrariadas, em resumo, em situações de grave crise, raramente tais emergências circunscreviam as opções dos governantes 
brasileiros a uma só escolha. O problema recorrente não era ignorar ou subordinar-se aos interesses internacionais, mas desenhar uma solução que, atendendo aos objetivos de nossos credores, minimizasse os prejuízos dos agentes econômicos nacionais. Ou seja, entre o amálgama de objetivos econômicos heterogêneos, estes com frequência incompatíveis, introduzia-se mais um elemento, a política, a negociação entre os atores internos e a viabilização de uma alternativa capaz de manter a coesão interna das elites da Primeira República.

A recusa do reducionismo da explicação "colonialista" vai de par com igual recusa do reducionismo do modelo "café com leite", segundo o qual a história do período não ultrapassaria a rubrica de folhetim, financiada pela economia cafeeira, em que o enredo era sempre o mesmo - a Presidência da República indo para São Paulo, que a transferia a Minas Gerais, que a devolvia a São Paulo, e assim por diante-, alterando-se apenas, e nem tanto, os atores em cena. A literatura revolucionária, partidária da Revolução de 30, foi extremamente eficiente ao fixar na memorialística nacional a imagem de que o período correspondente à Primeira República foi nefasto, controlando o país por não mais do que duas ou três "carcomidas" (termo da literatura revolucionária) oligarquias estaduais, ocupadas em manter privilégios, ainda que com o comprometimento dos interesses gerais do país. É dessa literatura que decorre a designação de "República Velha", sendo esta na verdade a primeira república, e que só encontrará sucessora, 15 anos depois de haver sido destruída, na restauração política de 1945.

\section{A "OLIGARQUIA" COMO SISTEMA: PROBLEMAS CONCEITUAIS}

Os revolucionários de 1930 referiam-se aos membros da elite destituída como oligarcas, do mesmo modo que, depois da Constituinte de 1987-88, se tornou usual identificar a classe política do período 1945-1964 como a representante da oligarquia hegemônica no Brasil de então. "Oligarca" e "oligarquia", a literatura especializada o comprova, são termos carentes de significado preciso e consensual na história brasileira. Nenhuma originalidade na literatura, a propósito, pois o tratamento que os cientistas políticos e historiadores dão a suas histórias nacionais reproduz o mesmo hábito. A fonte da desajeitada periodização e nomenclatura é a mesma: ausência de clara definição e aceitável estudo do que seja e de como funciona um sistema oligárquico. 
Todos os construtores de tipologias, agora como no passado, são leais e fiéis discípulos de Aristóteles, segundo o qual, as comunidades políticas são governadas por um, alguns ou muitos. O critério numérico garantiria a distinção entre as três maiores e relativamente contrastante classes de governo. Em obediência à exigência ainda aristotélica de que classes logicamente legítimas (ou conjuntos) de fenômenos devem ser mutuamente exclusivas e em si mesmo exaustivas, as tipologias aceitáveis estarão também submetidas aos três princípios básicos da lógica de Aristóteles: o princípio da identidade, da não contradição e do terço excluído.

Nem sempre, todavia, os comandos da boa lógica podem ser obedecidos no tratamento de fenômenos da vida real. O contemporâneo ramo da "lógica dos conjuntos nebulosos", que estuda os fenômenos não regidos pelo princípio do terço excluído, busca justamente reduzir a arbitrariedade que o abandono do princípio produziria. Mas não se trata aqui de desafiar a lógica de Aristóteles, mas seu critério numérico de classificação de governos.

Péricles, o grande líder grego, pertence à galeria de notáveis figuras cuja acme (maturidade) se dá no florescente período da democracia ateniense, afastados os aristocratas e os oligarcas dos instrumentos de poder. Aclamado e várias vezes reeleito para o posto de piloto (equivalente, mais ou menos, a comandante em chefe, civil e militar) da cidade, não foram poucos os intelectuais de seu tempo, inclusive seu grande amigo, o historiador Tucídides, que entenderam seu longo período de governo como uma espécie de benévola e implicitamente aceita tirania (os gregos não possuíam uma palavra para "ditador"). Se o governo de Péricles não atendia inteiramente aos critérios da época de "democrático", por certo seria historicamente despropositado considerá-lo um governo tirânico, ou ditatorial, em sentido moderno. Na verdade, era o critério numérico que se revelava, ainda antes que Aristóteles viesse a consagrá-lo, como insuficiente para classificação de governos. Não obstante, remodelado, disfarçado ou sofisticado, o critério numérico continua sendo, mesmo hoje, a única âncora da teoria da democracia para distingui-la, por princípio, de uma oligarquia.

Esquecida a premissa maior - o critério numérico de classificação - diferenças adjetivas, embora importantes, ressaltam da comparação entre democracias e oligarquias, tal como convencionalmente aceitas: nível de participação, lisura eleitoral, financiamento do governo etc. 
Mas, não sendo lógica e teoricamente impossível que um governo oligárquico possa apresentar características semelhantes às das democracias: lisura no trato dos recursos públicos, nas eleições etc., só restará, de fato, a diferença no número de participantes. Esta é a premissa crucial da distinção e o que transforma a democracia em um rebento estritamente evolutivo da oligarquia. Mais ainda: o critério numérico é a razão fundamental pela qual os teóricos da democracia não podem se evadir da conclusão de considerar a oligarquia, o governo de uns poucos, como a democracia em botão. As consequências lógicas desta filiação constituem sérios embaraços à teoria da democracia.

Os conceitos de participação, consentimento e representação estão confundidos desde o início da experiência de participação em negócios do Estado por outros que não os reis e as autoridades eclesiásticas. A experiência está associada à interrogação sobre qual seria o sentido da participação senão o de dar conselho e assentimento a decisões do Estado, e quais as obrigações, incluindo a de representar ou não terceiros, que cabiam aos novos partícipes. Retomado nos séculos XI e XII, para final consagração constitucional no século XIII, foi a necessidade de obter auxílio em decisões de alta complexidade que fez reviver o princípio da Constituição de Justiniano, de 531, segundo o qual "o que afeta a todos deve ser aprovado por todos". Graciano, um dos iniciadores da escola de Direito de Bolonha, retomará o princípio do "quod omnes tangit ab omnibus debet comprobari" (QOT), em sua obra Decretum, publicada cerca de 1140, na qual é feito excepcional esforço para consolidar o Direito da Igreja, buscando-se encontrar "a concordância entre os cânones discordantes", isto é, o denominador comum entre normas contraditórias emitidas por diferentes representantes eclesiásticos no período em que a autoridade da Igreja ainda não estava centralizada. O princípio QOT não mais estará ausente dos debates constitucionais da Idade Média desde então. É certo que a antiguidade do princípio é vetusta, sendo sua origem anterior a Justiniano, mas 531 será a data referência para registro, quando ele for evocado nas sucessivas e frequentes convocatórias de assembleias por parte de reis e papas durante o século XII e até a famosa conclamação de Eduardo I, em 1295, que resultou na criação simbólica do Parlamento Modelo, nascido na Inglaterra. A erudição histórica confirma não corresponder a efeméride à ordem dos acontecimentos (tendo o QOT servido de justificativa para conclamações anteriores), sendo mais relevante, todavia, o reconhecimento de que os parlamentos não surgiram inteiramente de projetos jurídicos ou políticos elaborados pelos especialistas do Direito 
Canônico nem pelos juristas seculares. Tampouco foi o resultado irrefletido da agregação circunstancial de certo número e tipos de pessoas que poderiam, valesse estritamente o acaso, ser completamente diferentes. Não, os convidados aos concilia, ou conclaves, poderiam ser substituídos por outros indivíduos, mas não socialmente diferentes. Essa era a natureza dos parlamentos cujo objetivo nunca foi o de encontrar a melhor forma de organizar o governo, mas de buscar resultados imediatos em favor dos interessados nas decisões e que, em última análise, assumiriam os custos delas (Marongiu, 1968:55)². Nesse contexto é que os parlamentos favoreciam a confirmação de acordos contratuais entre a assembleia, em nome do povo, e o rei, incluindo uma dotação de recursos financeiros ao rei em troca do compromisso deste de sancionar as medidas aprovadas pelo Parlamento (Marongiu, 1968:53).

À época, a pergunta sobre quais deveriam ser os convidados do papa ou do rei para discutirem negócios de Estado visava um conjunto não muito grande e bastante homogêneo de pessoas: nobres, proprietários, no caso de haver discrepância entre o primeiro e o segundo conjunto, príncipes, distinguindo-os dos nobres palacianos, altos magistrados, e, dependendo da cidade hospedeira do encontro, alguns poucos membros da classe alta local. Pelo fim do século XII, a regra de participação de todos os que arcariam com as consequências das decisões já se transformara em princípio geral de direito eclesiástico e público.

Dois aspectos potencialmente controversos e que serviriam de combustível a conflitos posteriores referem-se à doutrina firmada pelos canonistas de que a participação só tinha legitimidade em termos individuais, isto é, o membro de uma assembleia, conforme o princípio, só comprometia a própria responsabilidade na aceitação e cumprimento das decisões tomadas - o que aparece como lógica implicação da norma que requer a participação na decisão daqueles que serão seus executores e, também, servos dela. Ao mesmo tempo, negava-se força representativa à voz e opinião dos membros individuais das assembleias, por mais que fossem representativos de uma corporação ou região. O consentimento legítimo a uma decisão coletiva requer a participação individual, sem a mediação de representantes.

A segunda característica problemática aponta para a exigência de unanimidade como critério de decisão das assembleias convocadas conforme o princípio de que todos os atingidos por uma matéria deveriam 
participar das decisões sobre ela. O requisito tornou-se ao mesmo tempo mais necessário e difícil de ser atendido quando, a partir de inovação atribuída, não sem contestação, aos dominicanos, assembleias começaram a ser constituídas por membros que haviam sido eleitos em alguma instância inferior para falar em nome delas. A participação via representação, pelo menos parcial, foi uma inovação, ao que parece, paralela à constitucionalização do princípio Quod Omnes Tangit, vindo a se encontrarem as duas tradições no século XIV. Se a abertura para a participação via representação alargava o envolvimento, pelo menos simbólico, das comunidades representadas, facilitando o aumento no número de participantes de corpo presente, essa consequência favorável impunha custos crescentes à fidelidade ao critério de decisão por unanimidade, em algum momento flexibilizado para que se permitissem decisões por maiorias qualificadas.

A permanente interação entre prática e reflexão teórica ao longo dos dois séculos precedentes resultou na silenciosa reforma institucional constitucional em que conselhos deliberativos deixaram de ser convocados a critério de reis ou papas e adquiriram autonomia como órgãos constitutivos do Estado, lá pela metade do século XIV, quando, inclusive, já se tornara clara a grande disputa em torno do lugar da autoridade última das comunidades, se no papado, se nos conselhos eleitos. Quem estava qualificado para participar deles, mediante qual critério de seleção e como deveriam decidir foram questões que fixaram a agenda da grande transformação das organizações políticas autocráticas em organizações democráticas, processo que tomará, se examinado com rigor, seis séculos aproximadamente. Não sem haver, contudo, o interregno da monarquia absolutista, do século XVI ao XIX, em algumas nações.

A gradativa descentralização e criação de órgãos representativos, característicos da Alta Idade Média, serão interrompidas e substituídas por processos exatamente opostos, a partir do século XV, consubstanciados na instauração de monarquias absolutistas. Atualmente, o conceito de monarquia absolutista é mais objeto de disputa do que instrumento descritivo de uma realidade política, havendo, inclusive, autores que consideram mitológica a putativa existência de um sistema absolutista no passado. Em qualquer caso, há relativa concordância em que coincidem aproximadamente no tempo a expansão do comércio interno, que leva à delimitação física de fronteiras nacionais, e do comércio internacional, a eliminação das estruturas intermediárias de 
poder representativo e a centralização política na figura do monarca ${ }^{3}$. É pela negação de tal sistema sem intermediação e centralizado, e dando início a outro ciclo histórico, que se estabelecem os sistemas representativos modernos, inicialmente em sua face oligárquica ${ }^{4}$.

\section{O SISTEMA OLIGÁRQUICO: CONSTITUIÇÃO, DESEMPENHO E CRISE}

Durante todo o século XVII, já instalado o Parlamento como instituição legítima de auxílio ao governo real, as eleições inglesas foram, em sua maioria, indisputadas, isto é, somente um candidato se apresentava para ocupar o posto. Por esta métrica, um sistema representativo maduro, isto é, em que representantes de duas ou três facções econômica e socialmente dominantes disputam os lugares de representação, indicou um avanço nas rotinas políticas. Este foi o caminho percorrido pelos sistemas representativos, marcos de ruptura com um longo passado de organizações políticas autoritárias e, sempre, imprevisíveis. A transição de eleições sem concorrentes a eleições de competição restrita e a eleições efetivamente concorridas, quer pelo ângulo dos candidatos, quer pela perspectiva dos eleitores, resume o longo período iniciado, na Inglaterra, com o primeiro grande ato de reforma, de 1832, até 1924, quando, finalmente, com o direito de voto estendido às mulheres, ele se universaliza.

O mesmo trajeto será realizado, com maior ou menor velocidade, por todos os países ao ingressarem na era dos sistemas representativos. A superficial continuidade temporal do processo conduz à impressão de que a lógica de operação do sistema econômico-político é a mesma, ao longo de, pelos menos, dois séculos, limitando-se as mudanças a aspectos quantitativos, isto é, número de candidatos e número de eleitores. Na realidade, ao longo do processo dá-se importante modificação de sistema causal.

O conceito de sistema oligárquico serve a diversos padrões, ou patrões. Participa ao mesmo tempo do nebuloso conjunto de sistemas não democráticos, sendo, nesta capacidade, absorvido pelo conceito mais amplo de autoritarismo, perdendo-se a nitidez de sua diferença específica, e de outro elástico conceito, o de democracia representativa, da qual representaria o estágio primitivo. Em razão dessa ambiguidade essencial, visitante perpétuo de mundos antagônicos, o sistema oligárquico é ora criticado por seu caráter antidemocrático, ora generosamente apreciado como uma democracia em botão. Em qualquer caso, 
não existem muitas teorias de sistemas oligárquicos que os tomem como uma unidade tipológica com propriedades diferenciadoras internas, lógica própria e padrões de funcionamento distintos tanto do autocratismo histórico, quanto da democracia representativa moderna. A investigação sobre sistemas oligárquicos, em consequência, deve ser iniciada por clara profilaxia conceitual.

As definições operacionais para os dois primeiros dos três conceitos pertinentes: sistema representativo, sistema representativo oligárquico e sistema representativo democrático podem ser dadas sucintamente. Conceito crítico, assinalando a distinção entre os dois modos conhecidos, universais e de longa duração, de organizar a ordem política, o conceito de sistema representativo consagra compactamente os valores a que a civilização aderiu cumulativamente ao somar dos séculos. Antes de uma definição mais formal, é recomendável, portanto, a apresentação da lista de direitos por eles preservados: sistemas políticos representativos são complexos combinatórios de quatro predicados de direitos: de expressão, compreendendo todas as suas variantes; de organização, que compreende a liberdade de ir e vir, de reunião, de persuasão e recrutamento; de votar em eleições para ocupação de todos os cargos públicos submetidos a escolha popular; de ser votado para ocupar qualquer um desses lugares, atendidos os respectivos requisitos para preenchimento dos cargos. Parte integrante do conceito de "representatividade", exige-se que todos os predicados de direito estejam institucionalizados segundo o princípio das garantias mútuas, que é o exato contrário do princípio de ameaça de coação do Leviatã hobbesiano. A eficácia do conceito de política representativa supõe disciplinada obediência aos direitos liberais clássicos, salvaguardada por uma convenção civil: o princípio das garantias mútuas. Por ele, fica contratado, entre os membros da sociedade, que respeitarão reciprocamente a liberdade de cada um exercer os direitos constitucionalmente discriminados, incluindo os complexos combinatórios mencionados.

Expressando o conceito em definição semiformal, ele seria convenientemente descrito como segue:

Sistemas representativos distanciam-se de sistemas monárquicos, autocráticos, pela novidade de que os lugares de autoridade pública devem ser preenchidos por eleição, antes que por indicação do monarca; pela defesa do princípio de que a sucessão em tais postos também se faça pelo expediente eleitoral; e pela rejeição da necessidade de juiz incondicionado para garantia da fidelidade aos direitos contratados. 
Consagrado pelo hábito e pela eficácia na manutenção da ordem negociada, o princípio das garantias mútuas se revela suficiente para assegurar o cumprimento dos quatro conjuntos de direitos. O tremor institucional que a modéstia da definição oculta ocupou entre dois e três séculos para ser superado. Tanto porque os sistemas absolutistas com os quais a política representativa rompe reagem com violência à aposentadoria institucional, quanto pelas indecisões e experiências características do período imediato ao fim do absolutismo. Cenários mais utópicos do que realistas descreviam formas alternativas de vida em comunidade, nas quais era conspícua a ausência de poderes políticos institucionalizados e se tentava deduzir como seria o mundo social sem a presença do Leviatã. Naturalmente, a política representativa que veio a se instalar de maneira duradoura não estava prefigurada em nenhum cenário utópico, resultando, antes, de ensaios e conflitos reais sobre propostas controversas quanto à organização do novo mundo constitucional. Registre-se que a conquista do mundo americano, africano e asiático (séculos XVI e XVII) se faz vitoriosa em momento de inflexão do potencial de sobrevivência da ordem absolutista, carente de projetos para o longo prazo, e, se não institucionalmente obsoleta, já em posição defensiva diante do futuro. É durante esta névoa institucional, de violência cega (nenhuma das rebeliões contra as monarquias autocráticas, do século XVI ao século XVIII, trazia rascunhos não utópicos do que pretendiam instaurar em substituição à autocracia) que se cristalizam certos experimentos nas relações políticas, percurso no qual o sangrento parto inglês antiabsolutista, antes e depois da Revolução de 1688, serviu de ponto de referência não utópica. A política representativa que se inaugurava não pertencia a nenhuma evolução aprimorada da espécie "autocracia", mas estupenda erupção institucional destinada a extinguir a variante monárquico-absolutista do estoque de possíveis alternativas da vida comunitária.

O sistema representativo se materializou na história sob duas variantes, uma delas operada pelo poder oligárquico. Nela, todos os direitos característicos dos sistemas representativos são exercidos, tendo vigência, inclusive, o princípio das garantias mútuas. A especificidade da política representativa oligárquica consiste nas qualificações impostas aos membros da sociedade para que usufruam os direitos subscritos. Fazem parte da sociedade política, em um sistema oligárquico, intitulados a consumir o completo conjunto de múltiplos direitos, aqueles que atendam às exigências para que se qualifiquem como membros titulares do sistema. As exigências desdobram-se em requisi- 
tos de renda, de gênero, de educação, de raça, de naturalidade, entre alguns outros que possam ser acrescentados por sociedades específicas, atendendo a características que lhes sejam exclusivas.

Por suposto, a amplitude de um sistema oligárquico, como organização política, como polis, é bastante inferior ao tamanho da sociedade, dele estando excluídos, preliminarmente, os pobres, as mulheres, os analfabetos, os estrangeiros naturalizados e as etnias economicamente subordinadas, a saber, no mundo colonial e ex-colonial, as etnias negra, indígena e asiática. Para os participantes da elite, o sistema funcionava conforme os mandamentos do modelo constitucional em que se fundamentava, enquanto para o demos nacional, a sociedade maior, faltavam precisamente o voto e a vigência universal dos direitos constitucionais. Indico, como exemplo, qualquer uma das sociedades da América Latina do século XIX, estando claro que o conceito se aplica igualmente a todos os sistemas representativos europeus e do norte da América à mesma época, século XIX. São os grandes senhores de uma economia ainda parcamente diversificada, e de poucas fortunas, que constituem tanto o eleitorado quanto os potenciais candidatos a administar aqueles direitos e a fazer respeitar, sem violações entre eles, o princípio das garantias mútuas. Na ausência de um Estado autocrático legítimo, e, em particular, dada a inexistência de um exército profissional de porte razoável, as forças armadas paraoficiais, o poder coercitivo, caução em última instância do cumprimento das leis, ou de desobediências bem-sucedidas, pertenciam aos proprietários de grandes pastos e de grandes lavouras. Eram exércitos privados, capazes de, em emergências, traduzir o princípio das garantias mútuas, se necessário, em princípio de mútuas arbitrariedades. Estando a força bem distribuída, resultava conforme ao interesse de todos a preservação do princípio, como fiança de usufruto comum daqueles direitos limitados aos membros da sociedade política. É quando se instala na vida comunitária um dos axiomas da poliarquia de Robert Dahl, o instante analítico em que os custos de repressão ao adversário se tornam superiores aos custos de tolerá-lo. Pela concepção de sistema representativo recémexposto, o axioma poliárquico da tolerância expressa, genericamente, o princípio das garantias mútuas, responsável pela estabilidade de sistemas representativos, e não apenas do sistema democrático.

É indispensável registrar, para efeito de esclarecimento de um pré-juízo, que a representação em regime oligárquico é completa, embora restrita: os interesses legalmente reconhecidos estão não só incluídos 
nela, como a estabilidade do regime se sustenta, como é próprio da inclusão institucionalizada, pelo acordo unânime sobre quais deverão ser os excluídos. Sistemas oligárquicos estáveis atendem à fundamental exigência de todos os teóricos-de J. J. Rousseau a James Buchanan, de John Rawls e Robert Nozick - para que uma comunidade política seja reconhecida como uma entidade de limites claros: consentimento unânime sobre requisitos de pertencimento (e, pois, do complementar não pertencimento).

Um governo oligárquico, como todo governo, administra o bem comum, o bem coletivo, tal como este é entendido, obviamente, pelos membros da sociedade política oligárquica. Sua lógica, entretanto, caracteriza-se por ser precisamente o oposto da lógica das sociedades poliárquicas. A principal dificuldade para a produção de bens coletivos em sociedades complexas e de voto universal consiste em que é racional, para todos e cada um dos latentes beneficiários do bem coletivo a ser produzido, não participar das tarefas necessárias à sua produção. Em sociedades políticas oligárquicas, por suas características de serem, comparativamente, semelhantes a um pequeno grupo, e de cada membro possuir igual capacidade de retaliação e violência dos demais, o processo decisório se rege pelo princípio do mínimo divisor comum, aquele que reduz as divergências ao máximo que elas podem assumir para que o sistema continue a funcionar. O mínimo é, também, com frequência, o máximo divisor comum produtivo, isto é, corresponde àquelas circunstâncias em que qualquer outra divergência acima do mínimo tolerável vira razão suficiente para que a decisão seja sabotada pelos descontentes. Não é automático, entretanto, que decisões um pouco acima do mínimo divisor comum produzam conflitos ameaçadores à estabilidade da ordem oligárquica. Os custos de transação de negociar uma solução acima do mínimo, mas dentro do tolerável, serão maiores do que os de decisões espontaneamente redutoras de divergências, mas ainda contribuindo para a satisfação das partes.

Embora aplicadas perdulariamente, são escassas as definições precisas do conceito de oligarquia e as investigações sobre sua dinâmica ${ }^{5}$. De modo geral, supõe-se que a etimologia da palavra, que se refere a alguns, ou poucos, seja suficiente para identificar o objeto sob análise. Até certo ponto, é. Contribui também para esclarecer o conceito e o convencional método de identificar os membros da oligarquia de acordo com suas relações de parentesco ou padrões de frequência de interações. Cliques, "clubes", "igrejas" serviriam como sinônimo, ou ma- 
quete simplificada, de oligarquias, nas quais as decisões obedecem ao critério das maiorias. Pictorialmente convincentes, essas "sociedades" estão, entretanto, bem distantes de constituírem ordens oligárquicas, em sentido estrito. As sociedades representativas oligárquicas são complexas, com regras de funcionamento e dinâmica distintas das que presidem o funcionamento de clubes ou de cliques. Em sistemas oligárquicos, as decisões são, em geral, tomadas por unanimidade, salvo quando um ou dois recalcitrantes se rebelam - evento frequente nas histórias nacionais do Chile, da Argentina, da Colômbia, do Peru, enfim, de toda a América do Sul, ao longo do século XIX e inícios do século XX. Ressalvada a cláusula das barreiras à entrada nas sociedades políticas oligárquicas, das econômicas às de etnia, adianto a seguinte definição formal de sistemas representativos oligárquicos:

Sistemas oligárquicos são aqueles em que nenhum membro ou reduzido grupo deles é capaz de produzir um bem coletivo, ainda que o deseje, sem a cooperação de todos os demais; em contraste, pequeno subgrupo de oligarcas é capaz de impedir a produção de um bem coletivo, não obstante a cooperação, entre si, de todos os demais.

A radical diferença entre sistemas formalmente oligárquicos e grupos organizados semelhantes a clubes e cliques consiste, em primeiro lugar, no fato de que clubes não existem para produzir bens coletivos, senão por coincidência, e, em segundo lugar, porque a regra de decisão por maioria os faz parecer miniaturas de sistemas representativos democráticos, antes que oligárquicos. Finalmente, clubes e cliques se diferenciam de sistemas representativos porque, precisamente, não são representativos, mas exclusivos.

Breve reflexão identificará como "grupo oligarca puro" um puro grupo rousseauniano, no qual os membros estão atados, mesmo contra sua vontade, à regra da unanimidade em matéria de vida pública: ou bem o acordo entre os oligarcas é completo, ou, então, a produção do bem coletivo ficará comprometida. Assim, um sistema oligárquico caracteriza-se fundamentalmente pela assimetria entre produção e prevenção de um bem coletivo - o que é diferente da assimetria clássica entre produção e consumo do bem.

Flexibilizando a definição, dir-se-á que, em oligarquias, a produção de bens coletivos requer cooperação de maioria altamente qualificada para ser eficaz, o que, pela mesma razão, torna a decisão de produzi-los vulnerável à obstrução de ínfima minoria. Um sistema oligárqui- 
co funciona em processo decisório de exigentes requisitos para aprovação de medidas e leniente permissividade para vetos. Implícita encontra-se a condição de que os recursos políticos estejam razoavelmente dispersos e de magnitude mais ou menos equivalente entre os poucos atores participantes.

Os bens coletivos fundamentais em sistemas oligárquicos são os mesmos que atravessam os séculos de apropriação privada: ordem pública e previsibilidade na execução de contratos. A cada estágio, percebe-se que "ordem pública" é o sinônimo político do princípio representativo de garantias mútuas. O que constitui "ordem" pública varia, sem ultrapassar, porém, os limites que sustentam a estabilidade das regras para continuada apropriação de renda. Em sistemas representativos, esta garantia se corporifica nas regras para substituição das pessoas que administram as demais regras - simplesmente, as regras de competição pelo poder. Desde Hobbes passamos a saber que "poder" significa controle sobre futuros possíveis, de onde se segue que a estabilidade das instituições que regulam o conflito distributivo depende da estabilidade das regras do jogo político ${ }^{6}$.

Ora, a vantagem de sistemas oligárquicos consiste no reduzido número de competidores pelo poder, minimizando a imprevisibilidade do futuro, enquanto sua vulnerabilidade decorre do baixo custo de provocar "desordem". A concentração e a relativa equivalência de recursos entre poucos atores se revelam no axioma de tipo dahlsiano, mas contrário a ele, de que os custos da coerção, para qualquer um dos oligarcas, serão sempre inferiores aos custos de tolerar os adversários (quando se transformam em real ameaça). Sistemas oligárquicos, em consequência, são aqueles em que todos os agentes praticamente são $p i-$ votais: sem cooperação da grande maioria deles, o bem coletivo "ordem pública" (que inclui a dimensão "competição") não será produzido, mas qualquer um deles pode produzir o "mal coletivo" desordem no espaço político sob sua jurisdição.

É relevante retomar aqui a essencial distinção entre "bem" e "mal" coletivos: enquanto ninguém pode ser impedido de consumir o primeiro, uma vez produzido, ninguém pode evitar consumir o segundo, se produzido. Em termos clássicos, enquanto a produção de um bem coletivo é compulsória e seu consumo voluntário, contrariamente, um mal coletivo é voluntariamente produzido, mas compulsoriamente consumido. Se, em sistemas representativos poliárquicos, uma solução possí- 
vel para o problema da ação coletiva produtora de bens públicos coincide com a estratégia de evitar o consumo de um mal coletivo, em oligarquias, o objetivo de impedir a criação continuada de um bem coletivo é atingido por intermédio da produção localizada de um mal público.

Por definição, nenhum dos micropoderes oligarcas, ou seus representantes transoligárquicos, pode interferir nos custos de coerção localizados em outra jurisdição até torná-los superiores aos custos de tolerância, propiciando a eficácia das garantias mútuas. Nem é do interesse de nenhum oligarca intrometer-se em outros "feudos", pois tal medida serviria de precedente para interferências exógenas em sua jurisdição particular. A reincidência de violências localizadas, a "desordem" isolada, é, não somente banal, mas necessária à manutenção da "ordem" comum, isto é, à estabilidade de todas as regras, garantia de regularidade nos resultados dos conflitos distributivos. A condição necessária para que a desordem local não comprometa a ordem comum se encontra na dissociação entre a expectativa da ordem comum dos oligarcas e a desordem real produzida por cada um deles em particular, e esta dissociação só se sustenta enquanto for baixíssimo o grau de interdependência do sistema. Em outras palavras, para que a expectativa comum de "ordem" não seja abalada é necessário que a "desordem" local seja, também, isolada.

A unanimidade de ação ou aquiescência dos indiferentes é um requisito fundamental para a estabilidade pacífica de sistemas oligárquicos. Eis um microexemplo, apropriado a sociedades políticas oligárquicas, na qual a economia também é oligárquica: se, em uma convenção de três produtores, acorda-se aumentar a margem de lucro de seus produtos, coordenando os preços (sendo o bem comum dessa coletividade a equitativa taxa extra de lucro que irão obter), a traição de apenas um deles, mantendo os preços antigos, será o bastante para que o "bem coletivo", taxa extra de lucros, deixe de ser produzido.

No longo prazo, como em todos os processos, o desenlace é suicida. Um controle oligárquico bem-sucedido, eventual crescimento econômico, sem o qual, segundo as instituições que devem ser preservadas, não é possível acumular mais renda por via do conflito distributivo regular, cria as condições probabilísticas para que maior número de pessoas preencha as condições vigentes de "elegibilidade". Além de facilidades crescentes de acesso à educação, também organização e infor- 
mação convertem-se em bens democratizáveis e, nessa medida, pressionam automaticamente o eixo da elegibilidade. Eis exemplo elementar: pela legislação brasileira atual, todo alfabetizado, maior de 18 anos de idade, e filiado a partido político, torna-se automaticamente "elegível" (variando o patamar de idade em função do posto disputado).

A expansão econômica por via oligárquica representa, em verdade, uma programação para a morte que não pode ser cancelada, exceto por retrocesso a alguma forma de autocratismo. O limite da capacidade extrativa do governo central, via impostos diretos, limite estabelecido pela facilidade oligarca de produzir desordem, obriga a expansão da base a ser taxada indiretamente, o que equivale a favorecer a expansão dos negócios. Só pelo crescimento econômico é que se compatibilizam os interesses oligárquicos de acumular renda, sem aumentar impostos diretos, mobilizando-se a estrutura coletora e redistributiva do Estado, o qual, obviamente, deve ser mínimo, tecnicamente compreendido o conceito.

Lentamente, contudo, a expansão econômica gera mercados nacionais, aceleração na divisão social do trabalho e, consequentemente, o aparecimento de mecanismos de integração, minando-se imperceptivelmente o caráter compartimentalizado e regulado da produção. Um terrível fantasma passa a rondar a oligarquia: a competição. Complexidade social, concorrência e universalização da produção mercantil são os resultados inescapáveis de um sistema oligárquico bem-sucedido, sobre os quais brotam inéditas ações coletivas nas dependências de todos os cativeiros. Conter essa pressão natural exige violência institucionalizada a custos crescentes.

Multiplique-se o fenômeno para as jurisdições oligárquicas existentes e obter-se-á aumento na frequência de desordens locais simultâneas, e desordens simultâneas contaminam a expectativa comum sobre a estabilidade de futuros possíveis. Perturba-se a taxa temporal de desconto pela inflação do desconto político, e o cálculo privado de cada oligarca estimula a violência contra as instituições que regulam o conflito distributivo. Intensifica-se coercitivamente a taxa de apropriação de renda, difundem-se as manifestações de inconformismo (pois existem competidores reduzindo os custos de informação), aumenta a violência estatal, provoca mais desequilíbrio na taxa temporal de desconto e está criado o círculo "barato" da desordem oligárquica: cresce o número necessário de oligarcas cooperativos para criar a maioria qualificada capaz de 
assegurar a efetivação da ordem comum e torna-se, por isso mesmo, mais fácil

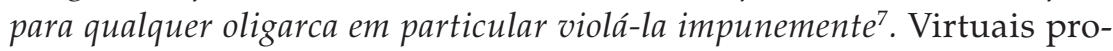
cessos de decadência oligárquica não têm prazo estipulado por antecipação. Um país pode permanecer estagnado por décadas, e estavelmente oligárquico, vindo a sofrer abalos por razões outras, tal como ocorrido no Portugal salazarista. Já a Espanha de Franco, igualmente longeva em seu autoritarismo, constitui caso exemplar de transição descontínua da oligarquia à poliarquia na sequência aqui descrita ${ }^{8}$. Conflito intraelite, apontado por todos os especialistas de área das décadas de 1950 e 1960 como variável crucial da estabilidade política, é o resultado inevitável do circulo da desordem oligárquica, abrindo-se dois futuros imediatos possíveis: ou se alarga a participação, aumentando o eleitorado, ou violam-se as regras institucionais do jogo de uma parte contra a outra da oligarquia.

Em resumo, é nesta dinâmica das decisões das oligarquias que a estrutura da economia representa importante papel. Em economias ainda muito próximas do modelo monocultor, herdados da época de submissão colonial, os interesses das poucas famílias abastadas são homogêneos, facilitando o exercício solidário e incontrastável do poder oligárquico. Progredindo a economia no sentido de maior pluralismo e mais complexa divisão do trabalho, aumentam os custos de transação para que se obtenha unanimidade, indicador infalível da eficácia do princípio das garantias mútuas. É usual, com a crescente fragmentação no padrão de demandas, de um lado, e a permanência de um sistema decisório altamente centralizado, de outro, que as decisões não litigiosas sejam de natureza reguladora, isto é, estipulem leis fixando os perímetros da economia e da sociedade, e a linha de tangência entre ambos, sob jurisdição de um grupo homogêneo de interessados, à exclusão dos demais. São estes agentes subnacionais, clãs parentais ou fortunas associadas, que passarão à condição de árbitros em última instância nos assuntos de sua competência e em sua reserva geográfico-social. E assim com todos os demais grupos, tudo resultando em uma divisão quase institucionalizada de fatias do poder entre os principais atores econômicos e sociais. Quando a estrutura econômica se pulveriza, perdendo pontos de referência em lideranças de maior porte, ou se confina a dois ou três grandes grupos de interesse conflitantes, aí se manifesta o tipo de instabilidade característica de sociedades políticas oligárquicas: sucessões desordenadas nas posições de poder, frequentemente contestadas, e a reincidência de golpes de estado, não necessariamente sangrentos, não sendo raro o retorno de líderes outrora ocu- 
pantes dos mesmos lugares. Desgasta-se o princípio de garantias mútuas, não mais servindo como indicador confiável, por sua frequente violação, do comportamento futuro de outros oligarcas. Ao contrário da versão dahlsiana da teoria da poliarquia, a regra das garantias mútuas não é um princípio de organização do poder poliárquico, mas de estabilidade da ordem política em geral. Por este prisma, nada há de incompatível com os fatos históricos registrar a possibilidade de longos períodos de dominação oligárquica sem utilização permanente de coerção hobbesiana.

\section{CRONOLOGIA PRELIMINAR DO SISTEMA OLIGÁRQUICO BRASILEIRO (1891-1930)}

Assentada a tese de que sistemas oligárquicos são variantes autônomas do ramo representativo, convém ordenar os episódios do período da Primeira República para fins de análise sistemática conforme o modelo aqui descrito. A ruptura entre a República e o Império, embora destituída do caráter espetacular de outras revoluções, está longe de ter significado não mais do que uma "jornada de tolos". A perplexidade causada pela ausência de grandiosos atos heroicos ou monumentais manifestações da população não deve ser interpretada como irrelevante substituição de formas de organizar o poder político. Institucionalmente, praticamente nada continuou como dantes, ao contrário do desapontamento manifestado por republicanos históricos. Naturalmente, a substituição de marcos institucionais da sociedade não produz efeitos instantâneos e de alta visibilidade na vida e na interação entre as pessoas. Se postos em comparação direta dois relevantes indicadores do modo de resolução de conflitos, a taxa de renovação dos membros da Câmara dos Deputados e a estabilidade governamental, anteriormente mencionadas, a diferença específica do sistema oligárquico brasileiro ficará evidente. Embora o Império, como forma de governo, tenha sido substancialmente estável, o exercício do governo foi, em comparação com a Primeira República, precário. A probabilidade de que um ministro de um gabinete imperial ficasse em seu posto até o fim do mandato do gabinete era de $0,32 \%$, menos da metade da probabilidade, igual a $0,68 \%$, de que um ministro da República continuasse em sua posição até o final do mandato presidencial. A quota média de renovação bruta da Câmara dos Deputados, durante o Império, e não obstante a quase impotência do Legislativo, foi de $0,65 \%$, bem superior à da Primeira República, em torno de $0,42 \%$. A possibilidade de que os agentes sociais mantivessem seus representantes a salvo do arbítrio 
central aumentou consideravelmente durante a Primeira República. Durante o Império, nada menos de $94 \%$ dos membros da elite que passaram pela Câmara não estiveram lá por, no máximo, dois mandatos. A porcentagem cai drasticamente para $57 \%$ durante os sucessivos legislativos republicanos. A estabilidade governamental e legislativa da Primeira República foi substancialmente superior à dos 63 anos de regime imperial.

Evidentemente, tal resultado só se torna visível após anos de operação do sistema, à medida que as instituições vão produzindo efeitos cumulativos. Daí a sensação inicial de que nada mudou com a implantação da República. Não obstante, a Constituição de 1891 é um dos documentos mais importantes da história política do Brasil. Com ela se estabelecem legalmente os ritos a serem obedecidos na administração e solução dos conflitos políticos, formulam-se mecanismos inteiramente inéditos de criação, extração e distribuição de riqueza (não necessariamente redistribuição), transfere-se poder e soberania do centro para os estados federados, algo que irá obrigar, precisamente, à estruturação de um sistema inteiramente distinto do sistema imperial. Os quarenta anos subsequentes fornecem uma excepcional base histórica para a investigação do modus operandi dos sistemas oligárquicos e da vida política real da Primeira República, tanto quanto possível livre dos preconceitos de que as elites que a sucederam a cobriram.

(Recebido para publicação em janeiro de 2013) (Aprovado para publicação em março de 2013) 


\section{NOTAS}

1. Para as mudanças ministeriais, por governo ver Santos, Robbs Filho e Rodrigues (2005:48).

2. A referência indispensável sobre as relações entre religião e instituições políticas é Tierney (1982).

3. A literatura é vasta, mas consultem-se, preliminarmente, Wilson (2000) e Monod (1999).

4. Duas das principais referências ao surgimento do Estado moderno e variantes de organização política são: Spruyt (1994) e Ertman (1997).

5. Ramseyer e Rosenbluth (1995) apresentam um dos raríssimos e, no caso, excelente, estudo sobre sistemas oligárquicos. Tratando-os pela ótica da teoria dos jogos, classificam tais sistemas como jogos com "núcleo vazio" (empty core), mas não vou discutir este modelo aqui.

6. Assinale-se ainda uma vez que esta é uma condição para a emergência da estabilidade em sistemas representativos, sejam oligárquicos, conforme a definição aqui adotada, sejam poliárquicos.

7. Por contraste ao free rider do bem público, estaríamos aqui às voltas com o problema do free driver do mal coletivo.

8. Ver, para Portugal, Maxwell (1995); para Espanha, ver o excelente estudo de Anderson (1970) e Maravall (1997, esp. cap. 2). 


\section{REFERÊNCIAS BIBLIOGRÁFICAS}

ALENCAR, José de. (1868), O Sistema Representativo. Rio de Janeiro, Garnier.

ANDERSON, Charles. (1970), The Political Economy of Modern Spain. Madison, The University of Wisconsin Press.

ERTMAN, Thomas. (1997), Birth of Leviathan - Building States and Regimes in Medieval and Early Modern Europe. Cambridge, Cambridge University Press.

JAPERI, Barão de. (1979), Organizações e Programas Ministeriais; Regime Parlamentar no Império. 1889 (3a ed.). Brasília, Departamento de Documentação e Divulgação, Instituto Nacional do Livro/Ministério da Educação e Cultura.

MARAVALL, José Maria. (1997), Regimes, Politics, and Markets. New York, Oxford University Press, 1997.

MARONGIU, Antonio. (1968), Medieval Parliaments: A Comparative Study. London, Eyre \& Spottiswoode.

MAXWELL, Kenneth. (1995), The Making of Portuguese Democracy. Cambridge, Cambridge University Press.

MONOD, Paul Kleber. (1999), The Power of Kings. Monarchy and Religion in Europe: 1589-1715. New Haven, Yale University Press.

RAMSEYER, J. Mark e ROSENBLUTH, Frances M. (1995), The Politics of Oligarchy: Institutional Choice in Imperial Japan. New York, Cambridge University Press.

SANTOS, Wanderley Guilherme (coord.); ROBBS FILHO, Carlos Frederico; RODRIGUES, Marcelle Marie Freitas. (2005), "Primeira República: Reflexões acerca da Elite Ministerial". Revista Candelária, ano I, no 3.

SARMENTO, Cléa. (1986), “Estabilidade Governamental e Rotatividade das Elites Políticas no Brasil Imperial". Dados, vol. 29, no 2, pp. 139-175.

SPRUYT, Hendrik. (1994), The Sovereign State and Its Competitors. New Jersey, Princeton University Press.

TIERNEY, Brian. (1982), Religion, Law and the Growth of Constitutional Thought: 1150-1650. Cambridge, Cambridge University Press.

WILSON, Peter H. (2000), Absolutism in Central Europe. London, Routledge. 


\begin{abstract}
The Oligarchic Representative System in the First Republican Period of Brazil

Between the absolutisms of the $17^{\text {th }}$ and $18^{\text {th }}$ centuries and the democratic variants identified after World War II, there remains a conceptual haze that hinders an understanding of the period's political and institutional history. With the oligarchy viewed sometimes as the seed of democracy and other times as a vestige of autocracy, the period remains vulnerable to subjectivisms. The current article presents a different, trans-locally valid analytical model for the oligarchic system and attempts to demonstrate how the history of the Second Empire and First Republic of Brazil would appear in a preliminary approach using the general model.
\end{abstract}

Key words: representative system; oligarchies; First Republic

\title{
RÉSUMÉ \\ Le Système Oligarchique de Représentation de la Première République
}

Entre les absolutismes des XVII ${ }^{\mathrm{e}}$ et XVIII ${ }^{\mathrm{e}}$ siècles, d'une part, et les variantes démocratiques repérées après la Seconde Guerre Mondiale, d'autre part, demeure un brouillard conceptuel gênant la compréhension de l'histoire politico-institutionnelle de cette période. L'oligarchie, traitée soit comme germe de démocratie soit comme vestige autocratique, reste une période soumise à la subjectivité. On présente un modèle analytique différent de ce que serait un système oligarchique, à la validité trans-locale, en cherchant à montrer la façon dont l'histoire du Second Empire et de la Première République apparaitrait au moyen d'une approche préalable utilisant le modèle général.

Mots-clés: système représentatif; oligarchies; Première République 